\title{
ANALYSIS OF TM NONLINEAR OPTICAL WAVEGUIDE SENSORS
}

\author{
Rahrovan Zahra', Shahmirzaee Hossein ${ }^{2}$ \\ ${ }^{1}$ Department of physics, Science and Research Branch, Islamic Azad University, Fars, Iran \\ ${ }^{2}$ Air Ocean Research Center, Shiraz, Iran
}

\begin{abstract}
In this paper, we offer an analytical theory to study three-layer slab waveguide for sensor applications. Proposed sensor consists of a linear thin dielectric film that is surrounded by a nonlinear asymmetric environment. We consider polarized waves TM and nonlinear environments as of Kerr type. We also investigate sensor sensitivity for maximum mood, nonlinear sensors have a higher sensitivity than linear sensors. This sensitivity in nonlinear sensors can increase up to 10/072\% compared to linear sensors.
\end{abstract}

Keywords: Sensitivity, Thin dielectric film, Sensor fiber.

\section{INTRODUCTION}

In the last two decades, optical waveguides have been studied severely as sensor elements and have been taken place due to the growth of the technology and fiber optic [15]. These sensors have been studied for different purposes including humidity sensors, chemical sensors and biochemical sensors[6-12]. These types of sensors have important applications in determination of protein absorption based on dependency of bacteria recognition or cells living. Also, they can be used for detection of ultrathin biological molecules layers of thickness much smaller than guidance light wavelength and detection of harmful gases like methane, $\mathrm{Co}_{2}, \ldots$. The privileges of these optical sensors are their immunity against electromagnetic interference, high sensitivity, small size and low price.

One of the important factors in the optical field is effective refractive index $\mathrm{N}$ witch will be resulted by the $\mathrm{N}=\frac{\mathrm{c}}{\mathrm{v}_{\mathrm{ph}}}$ equation. In this equation $\mathrm{C}$ is the light velocity in vacuum and $\mathrm{v}_{\mathrm{ph}}$ is the phase velocity. The main idea of planner dielectric waveguide sensor is measuring the changes in effective refractive index $\mathrm{N}$ due to changes in cover refractive index $n_{c}$. If a Light with the angle of alpha enter one of the ends of the waveguide in film part, it will be led within the film by total internal refraction which takes place at the boundaries of the film-cover and film-substrate. The mentioned light exits from the other end of the film in the angle of $\theta$ where the intensity is measured by a detector. The result of this devises will be the crude data which will be used in the drawing of the sensorgram chart [13-20].

Some of the injected light will be absorbed by the cover. Now if the cover was objected to an external evanescent field, the amount of the light absorption and phase displacement will change. These changes represent the density and the refractive index of the cover[21-23].

Now at this point an analysis will be performed to reach the best sensitivity by changing the properties of the system.
Afterwards the recommended sensor will be compared with the linear sensor of its own type.

\section{THEORY}

A schematic structure of the waveguide under consideration is shown in Figure 1. A guiding layer with permittivity $\varepsilon_{\mathrm{f}}$ and thickness $h$ is coated onto a nonlinear substrate with permittivity $\varepsilon_{\mathrm{nl} 3}$. A nonlinear cladding layer with permittivity $\varepsilon_{\mathrm{nl} 1}$ is coated onto the guiding layer. We will consider $\mathrm{p}$-polarized waves that propagate in the $\mathrm{x}$-direction (TM waves). The only nonvanishing components of the fields $\mathrm{E}$ and $\mathrm{H}$ are $\mathrm{H}_{\mathrm{y}}, \mathrm{E}_{\mathrm{x}}$, and $\mathrm{E}_{\mathrm{z}}$. Assuming the nonlinear dielectric functions to be of Kerr type, i.e., $\varepsilon_{\mathrm{nl} 1}=\varepsilon_{\mathrm{c}}+$ $\alpha_{\mathrm{c}}|\mathrm{E}|^{2}$ and $\varepsilon_{\mathrm{nl} 3}=\varepsilon_{\mathrm{s}}+\alpha_{\mathrm{s}}|\mathrm{E}|^{2}$, where $\alpha_{\mathrm{c}}$ and $\alpha_{\mathrm{s}}$ are the nonlinear coefficients of the cladding and substrate, respectively and $\varepsilon_{\mathrm{c}}$ and $\varepsilon_{\mathrm{s}}$ are the linear parts of the permittivities. To solve the nonlinear wave equation for the magnetic field $\mathrm{H}$, one can write $\varepsilon_{\mathrm{nl} 1}$ and $\varepsilon_{\mathrm{nl} 3}$ as :

$$
\begin{aligned}
& \varepsilon_{\mathrm{nl} 1}=\varepsilon_{\mathrm{c}}+\alpha_{\mathrm{c}}^{\prime}\left|\mathrm{H}_{\mathrm{y} 1}\right|^{2}, \quad \varepsilon_{\mathrm{nl} 3}=\varepsilon_{\mathrm{s}}+\alpha_{\mathrm{s}}^{\prime}\left|\mathrm{H}_{\mathrm{y} 3}\right|^{2} \\
& \frac{\text { nonlinear cladding }(z>h), \quad \varepsilon_{m 1}=\varepsilon_{c}+\alpha_{c}\left|H_{y 1}\right|^{2}}{\text { Linear Film }(0 \leq z \leq h)} \underset{\downarrow}{\stackrel{h}{\downarrow} x} \\
& \text { nonlinear substrate }(z<0), \quad \varepsilon_{n / 3}=\varepsilon_{s}+\alpha_{s}\left|H_{y 3}\right|^{2}
\end{aligned}
$$

Fig- 1: Schematic structure of nonlinear slab waveguide sensor.

Where $\alpha_{\mathrm{c}}^{\prime}=\frac{\alpha_{\mathrm{c}}}{\varepsilon_{\mathrm{c}} \mathrm{C}^{2} \varepsilon_{0}^{2}}$ and $\alpha_{\mathrm{s}}^{\prime}=\frac{\alpha_{\mathrm{S}}}{\varepsilon_{\mathrm{S}} \mathrm{C}^{2} \varepsilon_{0}^{2}}, \mathrm{C}$ is the speed of light in vacuum, $\varepsilon_{0}$ is the free space permittivity and $\mathrm{H}_{\mathrm{y} 1}$ and $\mathrm{H}_{\mathrm{y} 3}$ are the TM fields in the cladding and substrate, respectively. After solving Maxwell's equations in the three layers of the 
structure and matching the tangential magnetic and electric fields, the dispersion relations for $\alpha_{s}^{\prime}>0$ and $\alpha_{c}^{\prime}>0$ are given by:

$$
\begin{gathered}
\mathrm{k}_{0} \mathrm{q}_{\mathrm{f}} \mathrm{h}-\operatorname{rctan}\left(\mathrm{a} \frac{\mathrm{X}_{\mathrm{c}}}{\mathrm{a}_{\mathrm{c}}} \tanh \mathrm{C}_{\mathrm{c}}\right)-\arctan \left(\frac{\mathrm{X}_{\mathrm{s}}}{\mathrm{a}_{\mathrm{s}}} \tanh \mathrm{C}_{\mathrm{s}}\right)-\mathrm{m} \pi \\
=0
\end{gathered}
$$

Where $\mathrm{k}_{0}$ is the free space wave number, $\mathrm{q}_{\mathrm{f}}=\sqrt{\varepsilon_{\mathrm{f}}-\mathrm{N}^{2}}$, $\mathrm{N}$ is the effective refractive index, $\mathrm{C}_{\mathrm{c}}=\mathrm{k}_{0} \sqrt{\mathrm{N}^{2}-\varepsilon_{\mathrm{c}}}(\mathrm{h}-$ $\left.\mathrm{z}_{\mathrm{c}}\right), \mathrm{C}_{\mathrm{s}}=\mathrm{k}_{0} \sqrt{\mathrm{N}^{2}-\varepsilon_{\mathrm{s}}} \mathrm{z}_{\mathrm{s}}, \mathrm{z}_{\mathrm{c}}$ and $\mathrm{z}_{\mathrm{s}}$ are constants related to the field distribution in the covering medium and substrate, respectively, $\mathrm{m}=0,1, \ldots$ is the mode order, $\mathrm{a}_{\mathrm{s}}$ and $\mathrm{a}_{\mathrm{c}}$ are two asymmetry parameters and $\mathrm{X}_{\mathrm{s}}$ and $\mathrm{X}_{\mathrm{c}}$ are two normalized variables given by:

$$
\begin{gathered}
\mathrm{a}_{\mathrm{s}}=\frac{\varepsilon_{\mathrm{s}}}{\varepsilon_{\mathrm{f}}} \quad, \quad \mathrm{a}_{\mathrm{c}}=\frac{\varepsilon_{\mathrm{c}}}{\varepsilon_{\mathrm{f}}} \quad, \quad \mathrm{X}_{\mathrm{s}}=\frac{\sqrt{\mathrm{N}^{2}-\varepsilon_{\mathrm{s}}}}{\mathrm{q}_{\mathrm{f}}}, \\
\mathrm{X}_{\mathrm{c}}=\frac{\sqrt{\mathrm{N}^{2}-\varepsilon_{\mathrm{c}}}}{\mathrm{q}_{\mathrm{f}}}
\end{gathered}
$$

It is straightforward to show that $\mathrm{X}_{\mathrm{s}}$ and $\mathrm{X}_{\mathrm{c}}$ are interrelated by:

$$
X_{c}^{2}=\frac{\left(1-a_{c}\right)\left(1+X_{s}^{2}\right)}{\left(1-a_{s}\right)}-1
$$

The effective refractive index can be written in terms of $a_{s}$ and $\mathrm{X}_{\mathrm{s}}$ as

$$
\mathrm{N}=\sqrt{\varepsilon_{\mathrm{f}}} \sqrt{\frac{\mathrm{a}_{\mathrm{s}}+\mathrm{X}_{\mathrm{s}}^{2}}{1+\mathrm{X}_{\mathrm{s}}^{2}}}
$$

The sensitivity of the sensor $S_{h}$ is defined as the rate of change of the effective refractive index under an index change of the cover. Differentiating Eq. (2), with respect to $\mathrm{N}$ and calculating $\mathrm{S}_{\mathrm{h}}$ as $\left(\partial \mathrm{n}_{\mathrm{c}} / \partial \mathrm{N}\right)^{-1}$ we obtain:

$$
S_{h}=\frac{\sqrt{a_{c}} \sqrt{1+X_{c}^{2}} B}{X_{c} \sqrt{a_{c}+X_{c}^{2}} D}
$$

Where,

$$
\begin{gathered}
\mathrm{B}=\mathrm{a}_{\mathrm{c}} \mathrm{H}_{\mathrm{c}}+\mathrm{a}_{\mathrm{c}} \tanh \mathrm{C}_{\mathrm{c}} \\
\quad+2 \mathrm{X}_{\mathrm{c}}^{2} \tanh \mathrm{C}_{\mathrm{c}}\left(1-\mathrm{a}_{\mathrm{c}}\right) /\left(1+\mathrm{X}_{\mathrm{c}}^{2}\right) \\
\begin{array}{c}
\mathrm{D}=\left(\mathrm{a}_{\mathrm{c}}^{2}+\mathrm{X}_{\mathrm{c}}^{2} \tanh ^{2} \mathrm{C}_{\mathrm{c}}\right)\left(\mathrm{A}_{\mathrm{TM}}+\mathrm{G}_{\mathrm{sTM}}\right. \\
\left.+\mathrm{G}_{\mathrm{cTM}}\right)
\end{array} \\
\mathrm{H}_{\mathrm{c}}=\mathrm{k}_{0}\left(\mathrm{~h}-\mathrm{Z}_{\mathrm{c}}\right) \mathrm{X}_{\mathrm{c}} \sqrt{\varepsilon_{\mathrm{f}}} \sqrt{\frac{1-\mathrm{a}_{\mathrm{c}}}{1+\mathrm{X}_{\mathrm{c}}^{2}}}\left(-\tanh ^{2} \mathrm{C}_{\mathrm{c}}\right) \\
\mathrm{G}_{\mathrm{cTM}}=\frac{\mathrm{a}_{\mathrm{c}} \mathrm{H}_{\mathrm{c}}+\mathrm{a}_{\mathrm{c}} \tanh _{\mathrm{c}}\left(1+\mathrm{X}_{\mathrm{c}}^{2}\right)}{\mathrm{X}_{\mathrm{c}}\left(\mathrm{a}_{\mathrm{c}}^{2}+\mathrm{X}_{\mathrm{c}}^{2} \tanh ^{2} \mathrm{C}_{\mathrm{c}}\right)}
\end{gathered}
$$

$$
\begin{gathered}
\mathrm{G}_{\mathrm{sTM}}=\frac{\mathrm{a}_{\mathrm{s}} \mathrm{H}_{\mathrm{s}}+\mathrm{a}_{\mathrm{s}} \tanh \mathrm{C}_{\mathrm{s}}\left(1+\mathrm{X}_{\mathrm{s}}^{2}\right)}{\mathrm{X}_{\mathrm{s}}\left(\mathrm{a}_{\mathrm{s}}^{2}+\mathrm{X}_{\mathrm{s}}^{2} \tanh ^{2} \mathrm{C}_{\mathrm{s}}\right)} \\
\mathrm{H}_{\mathrm{s}}=\mathrm{k}_{0}\left(\mathrm{z}_{\mathrm{s}}\right) \mathrm{X}_{\mathrm{s}} \sqrt{\varepsilon_{\mathrm{f}}} \sqrt{\frac{1-\mathrm{a}_{\mathrm{s}}}{1+\mathrm{X}_{\mathrm{s}}^{2}}}\left(1-\tanh ^{2} \mathrm{C}_{\mathrm{s}}\right) \\
\mathrm{A}_{\mathrm{TM}}=\arctan \left(\frac{\mathrm{X}_{\mathrm{s}}}{\mathrm{a}_{\mathrm{s}}} \tanh \mathrm{C}_{\mathrm{s}}\right)+\arctan \left(\frac{\mathrm{X}_{\mathrm{c}}}{\mathrm{a}_{\mathrm{c}}} \tanh \mathrm{C}_{\mathrm{c}}\right)+\mathrm{m} \pi \\
=0
\end{gathered}
$$

The fraction of total power propagating in the covering medium is one of the most important quantities affecting the sensitivity of the sensor. For TM modes, the time averaged power flow in the $\mathrm{x}$-direction per unit width in the $\mathrm{y}$ direction can be expressed as

$$
\mathrm{P}=\frac{\mathrm{Nk}_{0}}{2 \omega \varepsilon_{0} \varepsilon_{\mathrm{r}}} \int_{-\infty}^{+\infty} \mathrm{H}_{\mathrm{y}}^{2} \mathrm{dz}=\mathrm{P}_{\mathrm{s}}+\mathrm{P}_{\mathrm{f}}+\mathrm{P}_{\mathrm{c}}
$$

Where $P_{s}$ is the power flow in nonlinear substrate and $P_{f}$ is the power flow in linear film.

The fraction of total power flowing in the nonlinear cladding is

$$
\frac{P_{c}}{P_{\text {total }}}=\frac{\frac{X_{c}}{a_{c} \alpha_{c}^{\prime}} \sigma_{c}}{\frac{X_{c}}{a_{c} \alpha_{c}^{\prime}} \sigma_{c}+\frac{X_{s}^{2} \operatorname{sech}^{2} C_{s}}{2 \alpha_{s}^{\prime}} r+\frac{X_{s}}{a_{s} \alpha_{s}^{\prime}} \sigma_{s}}
$$

Where $P_{s}$ is the power flow in nonlinear substrate and $P_{f}$ is the power flow in linear film

Where,

$$
\begin{gathered}
\mathrm{r}=\mathrm{k}_{0} \mathrm{q}_{\mathrm{f}} \mathrm{hx}_{+}+\frac{1}{2} \sin \left(2 \mathrm{k}_{0} \mathrm{q}_{\mathrm{f}} \mathrm{h}\right) \mathrm{x}_{-} \\
+\mathrm{X}_{\mathrm{s}} \mathrm{b} / \mathrm{a}_{\mathrm{s}} \tanh \mathrm{C}_{\mathrm{s}} \\
\sigma_{\mathrm{c}}=1-\tanh \mathrm{C}_{\mathrm{c}} \\
\sigma_{\mathrm{s}}=1-\tanh \mathrm{C}_{\mathrm{s}} \\
\mathrm{b}=1-\cos \left(2 \mathrm{k}_{0} \mathrm{q}_{\mathrm{f}} \mathrm{h}\right) \\
\mathrm{x}_{-}=\left(1-\left(\mathrm{X}_{\mathrm{s}}^{2} / \mathrm{a}_{\mathrm{s}}^{2}\right)\right) \tanh ^{2} \mathrm{c}_{\mathrm{s}} \\
\mathrm{x}_{+}=\left(1+\left(\mathrm{X}_{\mathrm{s}}^{2} / \mathrm{a}_{\mathrm{s}}^{2}\right)\right) \tanh ^{2} \mathrm{c}_{\mathrm{s}}
\end{gathered}
$$

\section{REPRESENTATION AND DISCUSSION}

To do the calculations, we have considered $\mathrm{Si}_{3} \mathrm{~N}_{4}$ and $\mathrm{GaN}$ as the guiding layer. The refractive index of the mentioned materials is respectively $\mathrm{n}_{\mathrm{f}}=2$ and $\mathrm{n}_{\mathrm{f}}=2 / 34949$. The free space wavelength $\lambda=1550 \mathrm{~nm}, \tanh \mathrm{C}_{\mathrm{c}}=0.6$ and $\tanh \mathrm{C}_{\mathrm{s}}=0.7$ is assumed. Due to the high sensitivity of the sensor, we considered fundamental mode $\mathrm{m}=0$. 
Covering and substratum medium are considered silica with different impurity percentages. It is necessary to mention that silica's linear and nonlinear dielectric constant is respectively $\varepsilon=2.13$ and $\alpha=7.04 \times 10^{-20}$.

In figure 2, we have plotted a chart which represents the sensor sensitivity according the thickness of the wave guide film. The subjected sensor is of the symmetric type $\left(\mathrm{n}_{\mathrm{s}}>\right.$ $\mathrm{n}_{\mathrm{c}}$ ). This diagram was compared linear sensor of it own type (figure 3). As you can see in the figure 2, the sensitivity of the nonlinear type is both higher and reachable at a thinner thickness of the film.

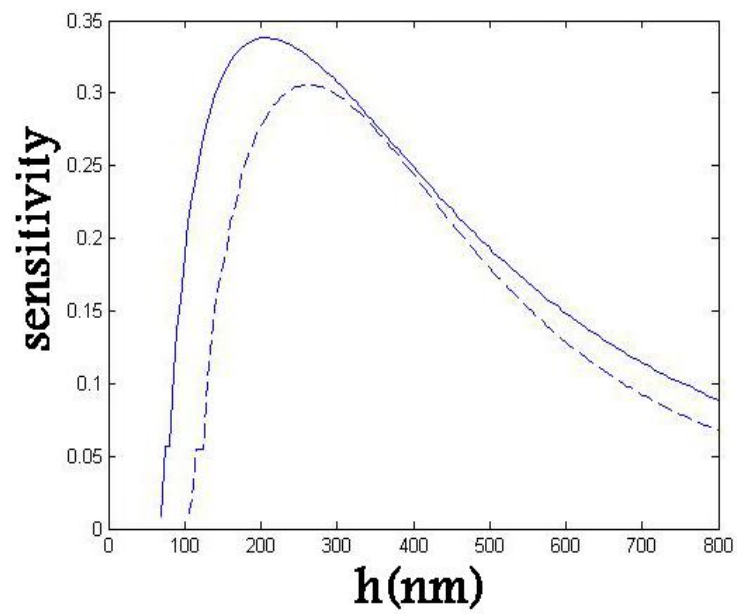

Fig- 2: Sensitivity versus the waveguide thickness $h$ for $\varepsilon_{c}=2 / 13$ and $\varepsilon_{s}=2 / 343\left(\mathbf{S i}_{3} \mathbf{N}_{4}, \mathbf{n}_{\mathrm{f}}=2\right)$ for the proposed nonlinear sensor and linear sensor (dotted line).

The comparison which is done in Figures 3 is very important and interesting. According to the diagram, nonlinear sensors $\mathrm{TM}_{0}$ have higher sensitivity in comparison with the $\mathrm{TE}_{0}$ kinds but this maximum sensitivity occurs in a thicker thickness of the film and this is a very important point at the designing of the sensors. This diagram has been drawn for both environments of conduct layer i.e. $\mathrm{Si}_{3} \mathrm{~N}_{4}$ and GaN which shows better sensitivity for GaN.
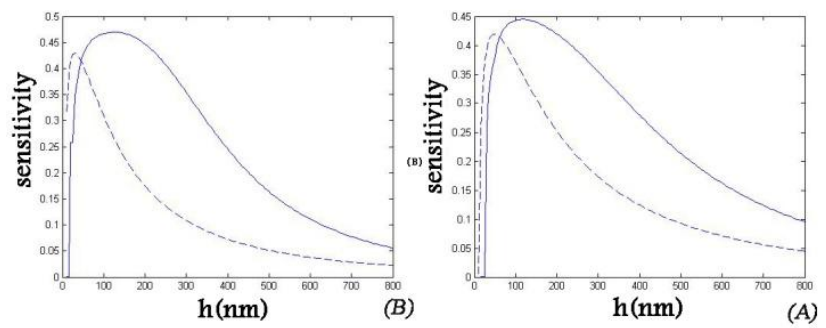

Fig- 3: Sensitivity as a function of waveguide film thickness for $\mathbf{T} \mathbf{M}_{\mathbf{0}}$ (solid line) and $\mathbf{T} \mathbf{E}_{\mathbf{0}}$ (dotted line) $\boldsymbol{\varepsilon}_{\mathbf{c}}=\mathbf{2} / 131917$, $\varepsilon_{\mathrm{s}}=2 / 14917 \mathrm{~A}-\mathbf{n}_{\mathrm{f}}=\mathbf{2},\left(\mathbf{S i}_{3} \mathbf{N}_{\mathbf{4}}\right)$ and B- $\mathbf{n}_{\mathrm{f}}=\mathbf{2} / \mathbf{3 4 9 4 9}$, $(\mathbf{G a N})$.

In figure 4 the sensitivity is plotted as a function of effective refractive index $\mathbf{N}$. The figure shows that the sensitivities are zero at $\mathbf{N}=\mathbf{1} / \mathbf{5 7}$ (this value of $\mathbf{N}$ occurs at cut-off since it is equal to $\mathbf{n}_{s}$, the figure is plotted for $\boldsymbol{\varepsilon}_{\mathrm{s}}=\mathbf{2} / 4495$, $\mathbf{n}_{\mathbf{s}}=\sqrt{\boldsymbol{\varepsilon}_{\mathbf{s}}}$ ) and at $\mathbf{N}=\mathbf{2}$ (this value of $\mathbf{N}$ is equal to the guiding layer refractive index). The sensitivities have their maxima somewhere between these two values near the cutoff and the values of the maxima of $\mathbf{N}$, and also the possession of this maximum depends on the value of $\mathbf{a}_{\mathbf{c}}$. This behavior of the sensitivity with $\mathbf{N}$ is explained by the power considerations discussed bellow.

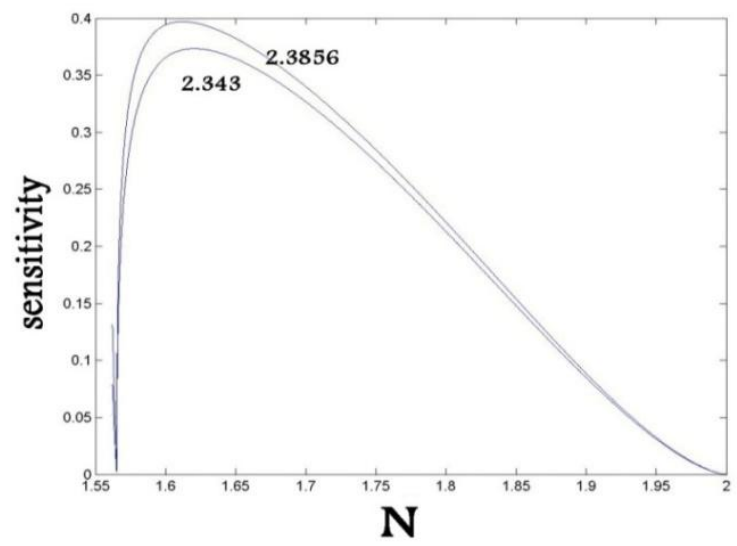

Fig-4 : Sensitivity versus the effective refractive index $\mathbf{N}$ for $\varepsilon_{\mathrm{c}}=2.8856, \varepsilon_{\mathrm{c}}=2.343$ and $\varepsilon_{\mathrm{s}}=2 / 4495, \mathbf{n}_{\mathrm{f}}=\mathbf{2}$

Figure 5 verifies the close connection between the fraction of total power propagating in the nonlinear cladding medium $\left(\mathrm{P}_{\mathrm{c}} / \mathrm{P}_{\text {total }}\right)$ and the sensitivity of the sensor. In most cases, they may be regarded as nearly identical thus the enhancement of the fraction of power flowing in the cladding is essential for sensing applications.
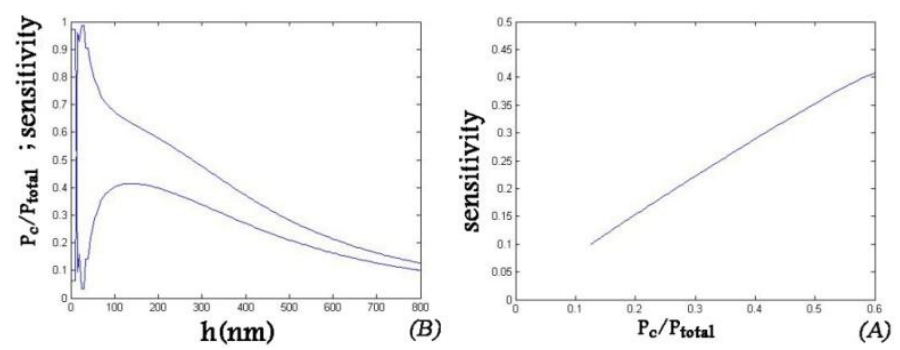

Fig- 5: Part A- sensitivity against the fraction of total power propagating in the cover medium, Part B-. the fraction of total power propagating in the cover medium as a function of the film thickness and the sensitivity as a function of the film thickness. $\left(\varepsilon_{\mathrm{s}}=2 / 3856, \varepsilon_{\mathrm{c}}=2 / 343, \alpha_{\mathrm{c}}^{\prime}=7 / 04 \times\right.$ $\left.10^{-21}, \alpha_{\mathrm{s}}^{\prime}=8 / 88 \times 10^{-21}, \mathrm{n}_{\mathrm{f}}=2\right)$

\section{CONCLUSIONS}

In this work, optical sensor of nonlinear three-layer slab waveguide has been studied. The thickness of guiding layer is a critical factor for the sensitivity of the optical sensor.

As shown in figure 2, nonlinear sensors have higher sensitivity than linearsensors ones. Sensitivity of linear and nonlinear sensors $\left(S_{h}\right)$ are respectively $0 / 3055$ and $0 / 3378$ that showa $10 / 572 \%$ increase in the sensitivity for the nonlinear sensors type. Thickness of nonlinear and linear sensors (h) are respectively $200 \mathrm{~nm}$ and $265 \mathrm{~nm}$ and that 
nonlinear sensor shows decrease in thickness as much as $24 / 528 \%$.

According to figure 3, nonlinear sensor sensitivity of $\mathrm{TM}_{0}$ mode has higher amounts than $\mathrm{TE}_{0}$ mode. Nonlinear sensor sensitivity in sensors with guiding layer $\mathrm{GaN}$ is higher than those with guiding layer $\mathrm{Si}_{3} \mathrm{~N}_{4}$. So sensors with guiding layer $\mathrm{GaN}$ and $\mathrm{TM}_{0}$ mode are recommended

\section{REFERENCES}

[1]. F. Yu, S. Yin, "Fiber optic sensors", Marcel-Dekker ,INC. New York.. BASEL,(2002).

[2]. B. Gholamzadeh, H. Nabovati, "Fiber optic sensors", World Academy of Science, Engineering and Technology, 42, (2008).

[3]. R. Horvath, H. C. Pedersen, N. Skivesen, D. Selmelzi, N. B. Larsen, "Optical waveguide sensor for on-line monitoring of bacteria", Opt. Lett. 28(14), 1233-1235, (2003).

[4]. S. A. Taya , T. M El-Agez, "A reverse symmetry optical waveguide sensor using a plasma substrate" , J. Opt. 13 075701, (2011).

[5]. M. M. Abadla, M. M. Shabat, D. Jäger, "Simulation of Sensing Characteristics in Optical Nonlinear Waveguide Sensors", Laser Physics, Vol. 14, No. 9, pp. 1231-1237, (2004).

[6]. W. Niu, M. Huang, Z. Xiao, L. Zheng, J. Yang, "Sensitivity enhancement in TE mode nonlinear planar optical waveguide sensor with metamaterial layer", Elsevier GmbH, pp. 547-552, (2011).

[7]. T. El-Agez, S. Taya, "Theoretical spectroscopic scan of the sensitivity of asymmetric slab waveguide sensors ", Optica Applicata, pp. 89-95, (2011).

[8]. S. A. Taya, M. M. Shabat, H. Khalil, "Nonlinear Planar Asymmetrical Optical Waveguides for Sensing Applications", Optik-International J. for Light and Electron Optics, pp. 860-865, (2010).

[9]. S. A. Taya, K. Y. Elwasife, "Guided modes in a metalclad waveguide comprising a left-handed material as a guiding layer", IJRRAS 13 (1), (2012).

[10]. M. M. Abadla, M. M. Shabat, D. Jäger, "Characteristics of Nonlinear Waveguide Sensors with Metallic Core Films", Laser Physics, Vol. 14, No. 12, pp. 1524-1528, (2004).

[11]. M. Abadla, M. M. Shabat, and D. Jäger, " In Proceedings of 3rd International Workshop on Laser Physics", Ham-burg, Germany , (2003).

[12] G. J. Veldhuis, O. Parriaux, H. J. W. M. Hoekstra, and P. V. Lambeck, "Sensitivity enhancement in evanescent optical waveguide sensor", J. Lightwave Tech. 18(5), pp. 667, (2000).

[13]. O. Parriaux, P. V. Lambeck, H. J. W. M. Hoekstra, G. J. Veldhuis, and G. Pandraud, "Evanescent wave sensor of sensitivity larger than a free space wave", Opt. Quantum, Electron. 32, pp. 909, (2000).

[14]. N. Skivesen, R. Horvath, and H. Pedersen, "Multimode reverse-symmetry waveguide sensor for broad-range refractometry", Opt. Lett. 28(24), pp. 2473, (2003).
[15]. R. Horvath, L. R. Lindvold, and N. B. Larsen, "Fabrication of all polymer freestanding waveguides", J. Micromech. Mircoeng. 13, pp. 419, (2003).

[16]. S. A. Taya, T. M. el-agez, "Comparing optical sensing using slab waveguides and total internal reflection ellipsometry", Turk J Phys, 35, pp. 31 - 36, (2011).

[17]. K. Schmitt, C. Hoffmann, "High-Refractive-Index Waveguide Platforms for Chemical and Biosensing", Springer-Verlag Berlin Heidelberg, (2010).

[18]. M. M. Abadla, M. M. Shabat, "Design and characterization of homogenous TM nonlinear waveguide sensors", ICAR/ 4, INTENAL REPORT (Limitted Distribution), (2004).

[19]. V. Brioude , O. Parriaux, "Normalised analysis for the design of evanescent-wave sensors and its use for tolerance evaluation", Optical and Quantum Electronic 32, pp. 899908, (2000).

[20]. N. Skivesen, , "Metal-Clad Waveguide Sensors" ,RisøPhD-15 (EN), pp. 23-24, (2005).

[21]. S. A. Taya, T. M. el-agez, H. Kullab, M. M. Abadla, M. M. Shabat, "Theoretical study of slab waveguide optical sensor with left-handed material as a core layer", Optica Applicata, Vol. XLII, No. 1, (2012).

[22]. S. A. Taya, T. M. el-agez, "Reverse symmetry optical waveguide sensor using plasma substrate", Journal of Optics 13(7), (2011).

[23]. S. A. Taya, T. M. El-Agez, "Optical sensors based on Fabry-Perot resonator and fringes of equal thickness structure", Optik - Int. J. Light Electron Opt., (2011). 